\title{
Duplicação da rodovia dos Tamoios-SP: fluidez e repercussões no espaço regional da Região Metropolitana do Vale do Paraíba e Litoral Norte
}

\author{
Duplication of the Tamoios Highway-São Paulo: \\ smooth traffic flow and repercussions on the regional area \\ of the Metropolitan Region of Vale do Paraiba and North Coast
}

Marco Antonio Henrique Adriane Aparecida Moreira de Souza Paulo Romano Reschilian

\section{Resumo}

A região do Vale do Paraíba possui uma das mais extensas e complexas redes urbanas do estado de São Paulo. Sua atual configuração resulta de processos históricos relacionados a atividades econômicas que promoveram maior articulação da Região com outras localidades do País. Na última década, a ampliação da rodovia dos Tamoios e as melhorias implantadas no porto de São Sebastião, localizado no Litoral Norte do estado de São Paulo, conferiram uma nova dinâmica às interações econômicas inter e intrarregional. Este artigo, derivado de um estudo em andamento, dedica-se a construir uma síntese dos processos de ocupação e de implantação de infraestrutura de transportes, correlacionando-os ao desenvolvimento econômico urbano-regional da atual região metropolitana do Vale do Paraíba e Litoral Norte.

Palavras-chave: configuração territorial; infraestrutura de transportes; interações econômicas; redes urbanas; fluidez.

\begin{abstract}
The Vale do Paraiba region has one of the most extensive and complex urban networks of the state of São Paulo. Its current configuration results from historical processes related to economic activities that promoted a greater articulation between the region and other localities in Brazil. In the last decade, the expansion of the Tamoios Highway and improvements in the Port of São Sebastião, located on the north coast of the state of São Paulo, have given a new dynamic to both inter-regional and intra-regional economic interactions. This article, which derives from an ongoing study, aims to build a synthesis of the processes of occupation and implementation of a transportation infrastructure, correlating them with the urban-regional economic development of the present Metropolitan Region of Vale do Paraiba and North Coast.
\end{abstract}

Keywords: territorial configuration; transportation infrastructure; economic interactions; urban networks; smooth traffic flow. 


\section{Introdução}

0 processo de ocupação e da formação de uma rede de vias de circulação na região do Vale do Paraíba Paulista vincula-se ao desenvolvimento de atividades econômicas realizadas em outras localidades do Brasil no período colonial, sobretudo, da mineração ocorrida no estado de Minas Gerais. 0 escoamento da produção em direção ao porto de Parati no estado do Rio de Janeiro passava pela região, bem como por ela passavam produtos provenientes de outras regiões do estado de São Paulo em direção à área da mineração. É nesse período que, segundo Müller (1969), surgem os primeiros e pequenos núcleos de urbanização na região do Vale do Paraíba Paulista.

Com a produção cafeeira no século XIX, essa região vivencia a chegada de um significativo contingente populacional proveniente das zonas de mineração, cuja atividade entrara em declínio. A atividade cafeeira criou as bases econômicas e um conjunto de infraestrutura, principalmente viária, necessárias para a intensificação do processo de urbanização e, mais tarde, no século XX, para a formação dos primeiros núcleos urbano-industriais na região.

Este artigo objetiva construir uma síntese dos processos de ocupação e de implantação de infraestrutura de transportes, correlacionando-os ao desenvolvimento econômico urbano-regional da atual região metropolitana do Vale do Paraíba e Litoral Norte (RMVPLN).

Para isso, inicia-se com uma breve discussão acerca dos ciclos econômicos e do processo de ocupação territorial no Vale do Paraíba, ainda no período colonial, para chegar ao Brasil do século XX e à sua economia industrial.
Em seguida, o artigo apresenta uma caracterização da RMVPLN, apontando, como aspecto favorável ao desenvolvimento econômico, sua localização geográfica, entre os dois maiores polos econômicos do País, Rio de Janeiro e São Paulo, e a relativa proximidade de municípios industrializados com o Litoral Norte do estado de São Paulo, mais especificamente com o porto de São Sebastião, o qual, há várias décadas, facilitou o acesso a equipamentos e máquinas, entre outros, e o escoamento da produção industrial realizada na região. Cabe ressaltar que a região possui ainda importantes vias, como as rodovias Presidente Dutra, dos Tamoios, Carvalho Pinto e Dom Pedro I, que favorecem as relações econômicas inter e intrarregionais.

Por fim, o artigo busca, ainda de forma exploratória, relacionar os projetos de duplicação da rodovia dos Tamoios e de melhorias do porto de São Sebastião - promovidos, respectivamente, pelo governo do estado de São Paulo e pelo governo federal -, à dinâmica econômica regional, tendo como perspectiva que tais obras representam principalmente, para os municípios mais industrializados da RMVPLN, uma possibilidade de ampliação dos fluxos de mercadorias, ao mesmo tempo que, para os municípios de Caraguatatuba e São Sebastião, mudanças nos aspectos socioespaciais e econômicos.

\section{Atividades econômicas na região do Vale do Paraíba Paulista: breve caracterização histórica}

A partir de meados do século XVII, com a interiorização e o surgimento dos primeiros núcleos 
urbanos a partir da Província de São Paulo de Piratininga, tem início o processo de ocupação da região do Vale do Paraíba Paulista. Esse processo é analisado por Müller (1969, p. 13) e por ele designado como a "expansão ecológica dos habitantes da área 'core'". A autora ressalta que a atividade mineradora e a necessidade de transporte de mercadorias para os núcleos mineradores e de sua produção em direção ao litoral estão entre fatores que contribuíram para o povoamento da região, possibilitando, dessa forma, iniciar uma articulação territorial em nível intra e inter-regional.

No século XIX, com a produção cafeeira, a região inicia um período de maior dinamismo econômico e demográfico. Para Müller (ibid., p. 30), esse dinamismo será marcado, ainda, pela intensificação do processo migratório a partir de Minas Gerais em razão da decadência da mineração. No entanto, no final do mesmo século, conforme esclarecido pela autora (ibid., p. 81) o declínio da produção cafeeira exige a criação de novas possibilidades econômicas. Com as bases criadas pela cafeicultura, entre as quais o acúmulo de capital, inicia-se o processo de industrialização, expandindo a ocupação da região.

A localização privilegiada da região do Vale do Paraíba, entre os dois principais polos econômicos do País - São Paulo e Rio de Janeiro -, contribuiu para que, no século $X X$, a região - mais especificamente, os municípios de Taubaté, São José dos Campos, Jacareí, Caçapava, Guaratinguetá e Pindamonhangaba, atravessados pela rodovia Presidente Dutra, inaugurada em 1950 -, se firmasse como uma das principais áreas da produção industrial no País.

Em 1968, a rodovia Presidente Dutra foi duplicada, implicando maior facilidade de escoamento de mercadorias e 0 acesso a matérias-primas utilizadas pelas indústrias, atraindo novas instalações e contribuindo para a diversificação da produção industrial na região (Souza, 2008).

A partir da década de 1960, por meio de medidas voltadas ao desenvolvimento econômico regional, orientadas pelo governo federal, a concentração industrial na Grande São Paulo começa a se dispersar em direção a outros municípios do interior do estado e de outras regiões do País. No entanto, conforme estudo de Costa (1982), o fenômeno de descentralização industrial a partir da cidade de São Paulo segue uma lógica estabelecida pelos eixos de transportes/circulação que se inicia na década de 1930, quando, por meio de um processo que o autor denomina "suburbanização industrial", cidades localizadas no entorno das ferrovias Santos-Jundiaí e Central do Brasil são atingidas. Costa (ibid.) esclarece que, na década de 1950, a descentralização industrial atinge municípios localizados próximos às rodovias Anchieta, Anhanguera e Presidente Dutra e, na década de 1960, municípios localizados a uma distância aproximada de $100 \mathrm{~km}$ da cidade de São Paulo, mais especificamente Campinas, Sorocaba e São José dos Campos.

Percebe-se, assim, uma relação profícua entre a produção industrial e a expansão dos eixos de transportes. A exemplo do apontado por Costa, que demonstra essa relação no estado de São Paulo, a partir da década de 1950, no País o que se verifica é a elaboração e adoção de políticas de transportes voltadas, predominantemente, à implantação de infraestrutura rodoviária. 0 desenvolvimento econômico com base na industrialização e o antigo projeto de integração nacional fomentaram o aumento e 
a criação de estradas de rodagem no País. A esse respeito, Santos e Silveira (2006, p. 69) afirmam que,

na segunda metade do século $X X$, a construção de diversas infraestruturas de circulação contribui para ligar as diversas regiões entre si e com a região Concentrada do País. É assim que a extensão da rede rodoviária brasileira passa de 302.147 quilômetros em 1952 para 1.657.769 quilômetros em 1995, sendo seu maior crescimento na década de 1970.

Santos e Silveira (ibid.) chamam a atenção, ainda, para a distribuição das estradas de rodagem no País, ressaltando que a maior extensão se encontra na região denominada "Concentrada", com destaque para o estado de São Paulo. A esse respeito, os autores esclarecem que "o ritmo de construção de rodovias desenvolvidas pela União foi acompanhado e mesmo ultrapassado, durante os anos 1960 e 1970, pelas políticas públicas do estado de São Paulo" (p. 65).

Continuando, os autores (ibid., p. 68) relacionam o desenvolvimento de atividades econômicas com a densidade rodoviária, mostrando que as atividades agrícolas e industriais explicam a densidade de rodovias municipais no estado de São Paulo, como revelam os municípios de São José do Rio Preto e Barretos, de forte produção agrícola, e municípios Campinas e São José dos Campos, de alto desenvolvimento industrial.

Dado o exposto, constata-se o papel da rodovia Presidente Dutra, na região do Vale do Paraíba Paulista, por colocar a região em contato com os principais centros econômicos do País, São Paulo e Rio de Janeiro. Ressalta-se, ainda, a relativa proximidade dos municípios do Vale do Paraíba Paulista com os localizados na área litorânea e, portanto, com o porto de São Sebastião, responsável, já na década de 1950, por abastecer os municípios industrializados com os insumos necessários à produção industrial, tais como sulfato de sódio, cereais, produtos siderúrgicos, máquinas e equipamentos, entre outros tipos de cargas.

Com a lei complementar estadual 1.166/2012 foi instituída a RMVPLN. Localizada no extremo leste do estado, ela é composta por 39 municípios, com as mais diversas características socioeconômicas e socioespaciais e os mais diferentes níveis de densidades demográfica, técnica, econômica, informacional.

\section{Região metropolitana do Vale do Paraíba e Litoral Norte (RMVPLN): interações inter e intrarregional}

Ao longo das últimas décadas, a região do Vale do Paraíba foi se constituindo num espaço heterogêneo, no que se refere aos aspectos econômicos e demográficos. Na região encontram-se municípios altamente industrializados e urbanizados, como São José dos Campos - reconhecido no Brasil e no exterior como o centro da tecnologia aeroespacial do País -, Taubaté, Caçapava, Jacareí e municípios cujas atividades econômicas predominantes são as desenvolvidas nas áreas rurais. Nessa situação, encontram-se os municípios de Natividade da Serra, Paraibuna, Jambeiro e Monteiro Lobato, cujo percentual da população rural, segundo dados do Instituto Brasileiro de Geografia e 
Estatística (IBGE, 2010), é superior ao da população urbana.

De acordo com a Empresa Paulista de Planejamento Metropolitano (Emplasa, 2012), tais contrastes regionais contribuíram para que, em 2012, fosse instituída a região metropolitana do Vale do Paraíba e Litoral Norte.
Composta por 39 municípios, essa região, segundo a Fundação Seade (Seade, 2017), possui uma população estimada em 2.425.293, distribuída em uma área de $16.192,67 \mathrm{~km}^{2}$ que corresponde a $32,41 \%$ da macrometrópole paulista, $6,52 \%$ do estado e a $0,19 \%$ da superfície nacional (Figura 1).

\section{Figura 1 - Localização da RMVPLN}

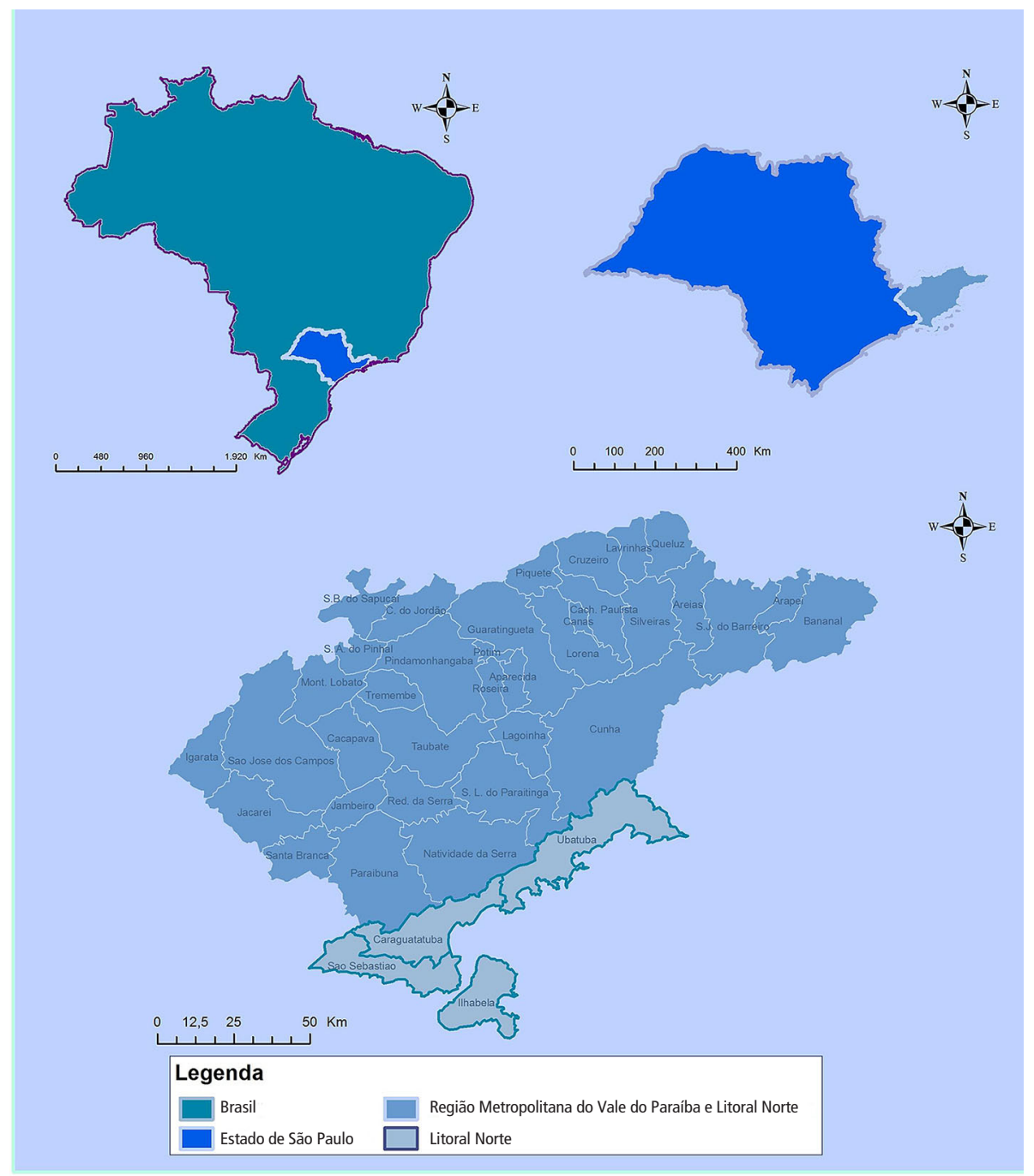

Fonte: IBGE (2010). Elaborado por Daniel José de Andrade, em 2017 (PPGPLUR - Univap). 
Em 2014, conforme dados da Fundação Seade, o Produto Interno Bruto (PIB) da RMVPLN correspondia a $R \$ 97.122 .765,14$, o que representava $5,22 \%$ do PIB do estado de São Paulo, cujo montante foi de $\mathrm{R} \$ 1.858 .196 .055,52$. Embora os números sejam expressivos, a distribuição do PIB é bastante desigual, fruto das diferentes atividades econômicas preponderantes em cada município. Em relação ao PIB per capita, dados do mesmo ano revelam que, na região, ele foi de $R \$ 41.178,14$, correspondendo a $94 \%$ do valor $\mathrm{R} \$ 43.544,61$ apresentado no estado de São Paulo.

No que diz respeito à qualidade de vida, dados de 2010 sobre educação, renda e longevidade do Programa das Nações Unidas para o Desenvolvimento (PNUD) revelam que, de um modo geral, os municípios da RMVPLN encontram-se numa faixa do IDHM considerada de alto desenvolvimento humano. Entre os 39 municípios, São José dos Campos, com 0.804 é o que apresenta o maior Índice de Desenvolvimento Humano Municipal (IDHM) e Natividade da Serra, com 0.655, o menor IDHM da região.

De acordo com a Emplasa (2012, pp. 71-92), são potenciais econômicos na RMVPLN as atividades turísticas; a produção industrial diversificada, com grande expressão nos setores dinâmicos da economia; os centros de pesquisa e desenvolvimento científico-tecnológico, especializados no setor aeroespacial; a oferta diversificada de produtos e serviços de consumo pessoal; a boa qualidade da água e do ar. A malha rodoviária existente na região permite o contato intrarregional, ao mesmo tempo que conecta a RMVPLN aos Aeroportos Internacionais de Guarulhos, SP, e Viracopos no município de Campinas, SP. A região é atravessada por importantes rodovias como a rodovia federal Presidente Dutra, rodovia dos Tamoios, rodovia Carvalho Pinto e rodovia Dom Pedro I (Figura 2). Na RMVPLN, desde 1955, o porto de São Sebastião constitui, segundo a Emplasa (ibid.) um dos portos de maior movimento e capacidade de transporte de petróleo e derivados da região Sudeste.

0 crescimento urbano acentuou-se nos últimos anos em razão do aumento das atividades industriais e do fluxo econômico regional. Multiplicaram-se, assim, as interdependências entre as diversas cidades. Na RMVPLN, o deslocamento pendular ocorre em razão da maior oferta de empregos e de instituições de ensino em determinadas cidades da região, sendo São José dos Campos, Taubaté e Jacareí os principais destinos.

Apenas para exemplificar, dos 39 municípios, segundo dados do ano de 2015 do Ministério da Educação (MEC), São José dos Campos com 16 unidades é o município que abriga o maior número de instituições de ensino superior na região, seguido por Taubaté e Jacareí, ambos com sete unidades.

As diversas rodovias e a grande infraestrutura de transportes possibilitam a ligação da RMVPLN como um todo a diferentes localidades do País, bem como, conforme o verificado, é forte a articulação entre os municípios que a compõem.

Historicamente, o porto de São Sebastião, localizado em município de mesmo nome, foi e continua sendo determinante para o contato da região com outras localidades do País e do mundo. 0 acesso ao porto ocorre por meio da SP-099, denominada rodovia dos Tamoios, cujo traçado ocorre entre as cidades de São José dos 
Figura 2 - Sistema de transportes na RMVPLN

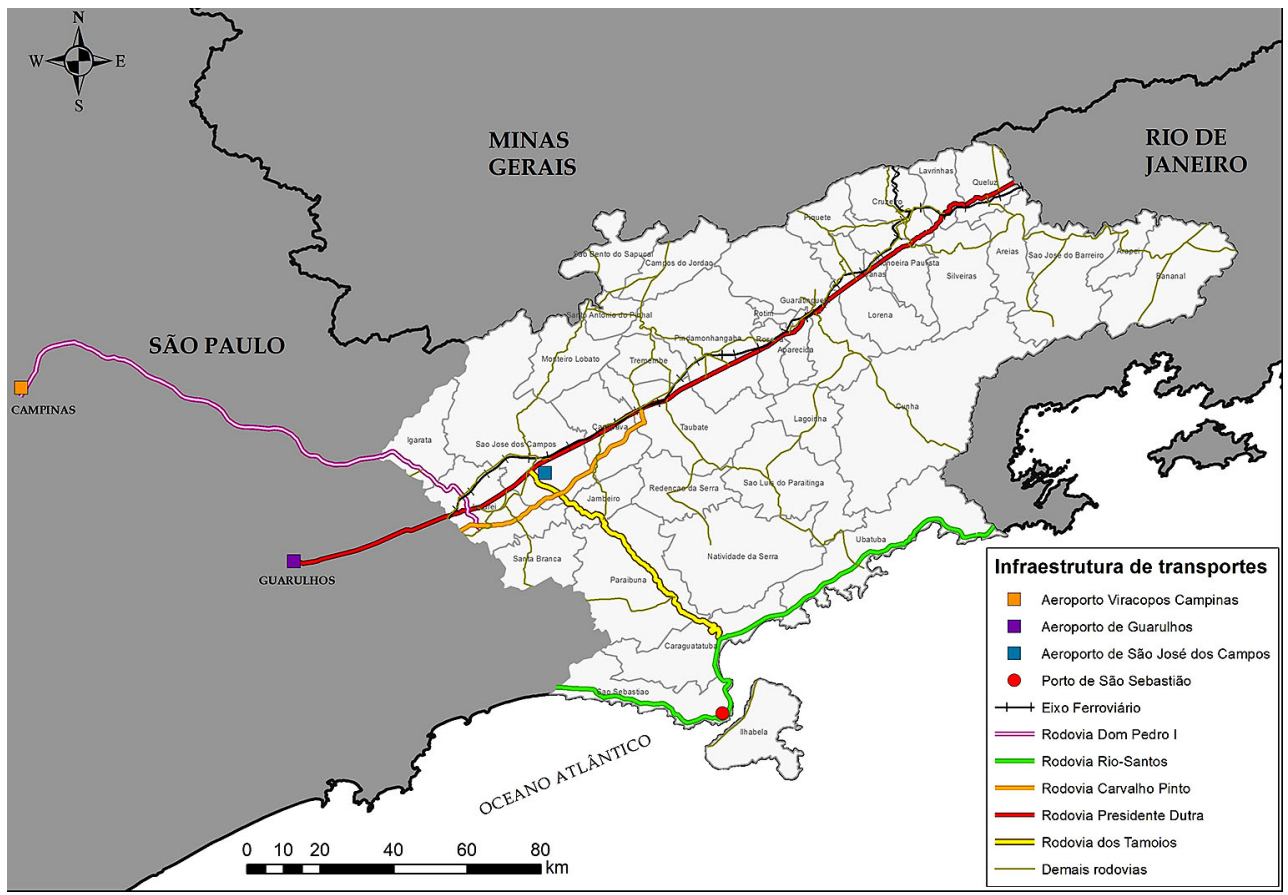

Fonte: IBGE (2010). Elaborado por Daniel José de Andrade, em 2017 (PPGPLUR - Univap).

Campos e Caraguatatuba. Desta última, a ligação ao porto de São Sebastião é realizada por meio da BR-101, conhecida como Rio-Santos.

\section{Rodovia dos Tamoios: transformações na paisagem urbano-regional e a articulação regional}

Implantada na década de 1930, a rodovia dos Tamoios liga os municípios localizados no eixo da rodovia Presidente Dutra aos localizados no litoral da RMVPLN. Com 82 km de extensão, a rodovia atravessa os municípios de São José dos Campos, Jambeiro, Paraibuna e Caraguatatuba e passa pelo extremo leste do município de Jacareí.

Desde a sua pavimentação em 1957, a rodovia dos Tamoios é o principal acesso ao porto de São Sebastião, utilizado para o escoamento da produção industrial, bem como para a entrada de maquinários e matérias-primas utilizados pelas indústrias localizadas no Vale do Paraíba Paulista, em especial, pelos municípios mais industrializados da região. 0 turismo nos municípios litorâneos é outra atividade econômica que também se desenvolveu a partir das melhorias implementadas na rodovia. 
Ao longo de sua existência, diversos trechos passaram por melhorias e até mesmo foram reconstruídos, como o ocorrido na década de 1960, quando uma forte chuva provocou o deslizamento de terras no trecho serrano da rodovia. Em 2012, iniciaram-se as obras de sua duplicação, a fim de atender às demandas de diversos segmentos produtivos, entre os quais o setor petroquímico, ${ }^{1}$ possibilitando maior acesso ao porto de São Sebastião, ${ }^{2}$ imprimindo nova dinâmica com o aumento dos fluxos na rodovia.

Em 2011, a empresa estatal Desenvolvimento Rodoviários S/A (Dersa) realizou diversas obras, na rodovia dos Tamoios, e serviços de duplicação de pontes, recapeamento da pista e dos acostamentos, somando 52,9 km de extensão. Em 2013, iniciou-se o projeto de duplicação, ampliação e futura concessão da rodovia. 0 Projeto Tamoios, como denominadas previamente a duplicação do trecho entre o município de São José dos Campos e a Serra do Mar no município de Caraguatatuba e, também, a construção, a partir do trecho de serra, de duas novas extensões, sendo uma referente ao Contorno Norte em direção ao município de Ubatuba e a outra ao Contorno Sul em direção ao município de São Sebastião. Ao todo, o Projeto Tamoios previa obras em área de $121 \mathrm{~km}$ de extensão (Dersa, 2017).

Figura 3 - Uso do solo no trecho da rodovia dos Tamoios km 45, Paraibuna-SP (2011)

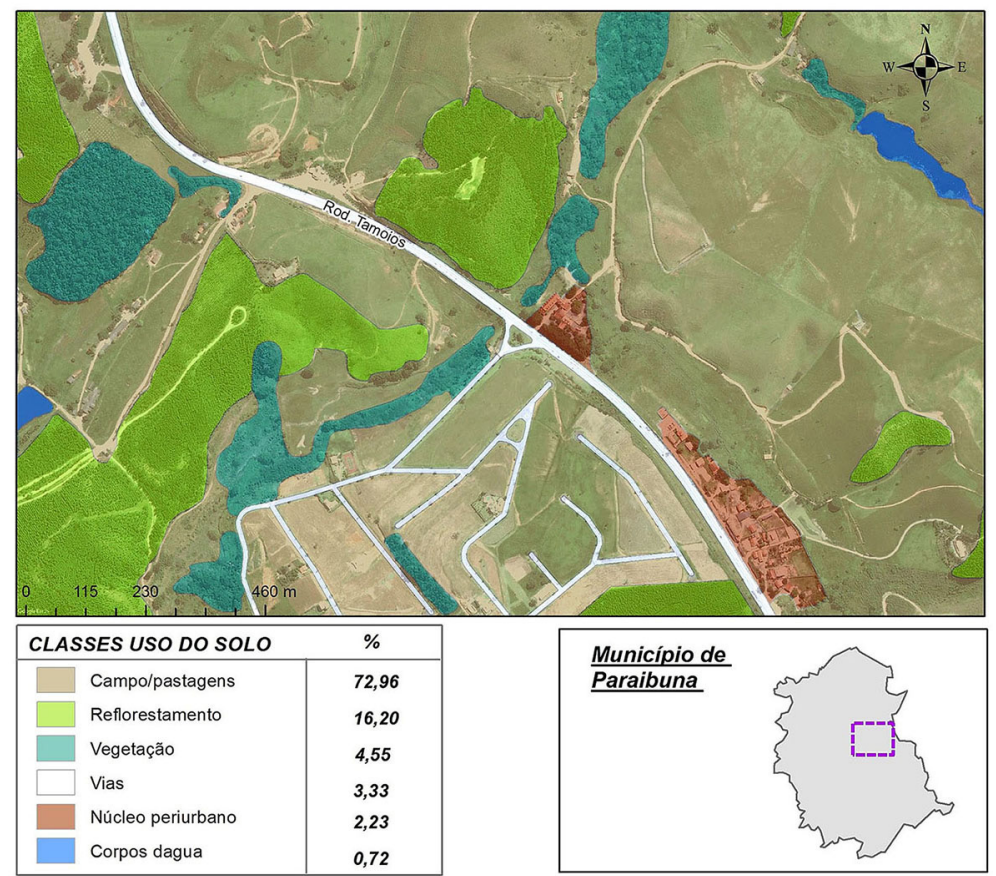

Fonte: Google Earth - maio de 2017. Elaboração: Daniel José de Andrade (PPGPLUR - Univap). 
Relatórios elaborados pela Companhia Ambiental do Estado de São Paulo (Cetesb), nos anos de 2011, 2012 e 2013, indicam os impactos sociais e ambientais que o empreendimento geraria. A desapropriação de terras ao longo de diversos trechos da antiga rodovia é apontada como uma necessidade ao projeto de duplicação, bem como para a implantação dos Contornos Sul e Norte.

0 parecer técnico 243/2011 sobre a área classificada como sub-trecho planalto, trecho da rodovia dos Tamoios que perpassa os municípios de São José dos Campos, Jacareí, Jambeiro e Paraibuna, previa, entre outras ações, a ampliação da largura das pistas e a implanta- ção de vias marginais, sobretudo, em trechos de adensamento urbano.

Imagens dos anos de 2011 e 2017 revelam as mudanças no entorno da rodovia, mais precisamente no $\mathrm{km} \mathrm{45,} \mathrm{em} \mathrm{período} \mathrm{anterior} \mathrm{e}$ posterior às obras de duplicação (Figuras $3 \mathrm{e}$ 4). Nessas figuras é possível observar a intensificação da ocupação da área no período de seis anos, em especial, o aumento do número de residências em condomínio de alto padrão localizado às margens da rodovia, bem como a implantação de uma passarela para pedestres.

Referente ao Trecho Serra, entre os km 60,48 e 82, nos municípios de Paraibuna e Caraguatatuba, o parecer técnico 221/2013 da

Figura 4 - Uso do solo no trecho da rodovia dos Tamoios km 45, Paraibuna-SP (2017)

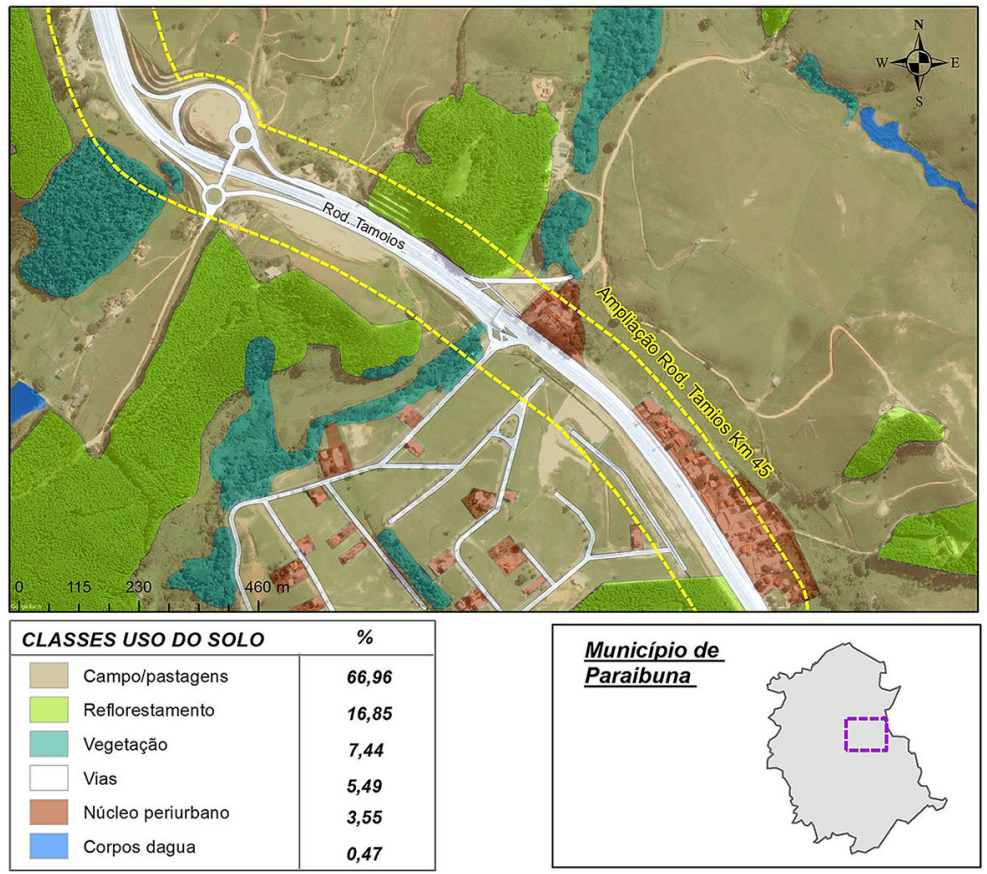

Fonte: Google Earth - maio de 2017. Elaboração: Daniel José de Andrade (PPGPLUR - Univap). 
Cetesb previa a implantação de uma segunda pista a partir no trecho de interseção com os Contornos Norte e Sul, totalizando aproximadamente 21,5 km de extensão (Figuras 5 e 6). Para o trecho de Serra, o Projeto contava ainda com a construção de cinco túneis no município de Caraguatatuba e em áreas do Parque Estadual da Serra do Mar (PESM).

Em toda a extensão do empreendimento, os traçados do Contorno Sul com 31,8 Km e do Contorno Norte com $6 \mathrm{Km}$ são os que perpassam áreas mais densamente ocupadas, sendo, portanto, áreas mais suscetíveis a desapropriação.

0 Contorno Norte, com apenas $6 \mathrm{~km}$ de extensão, corresponde a menor área de todo o empreendimento. Conforme parecer técnico 433 (Cetesb, 2012b, p. 54) o trecho se estenderá por solos rurais e por área urbana respectiva a diversos bairros do município de Caraguatatuba, afetando 36 ha e um total de 74 edificações (Figuras 7 e 8).

Referente ao Contorno Sul, informações obtidas no parecer técnico 352/2012 da Cetesb mostram que o referido acesso perpassará por solos rurais e se estenderá por área urbana respectiva aos bairros dos municípios de Caraguatatuba e São Sebastião, desapropriando 323 ha e um total de 1.222 edificações. Desse total, 398 edificações localizam-se nos bairros de Olaria, Itatinga, Topolândia e Morro do Abrigo do município de

Figura 5 - Uso do solo na rodovia dos Tamoios - Trecho Serra do Mar, Caraguatatuba-SP (2011)

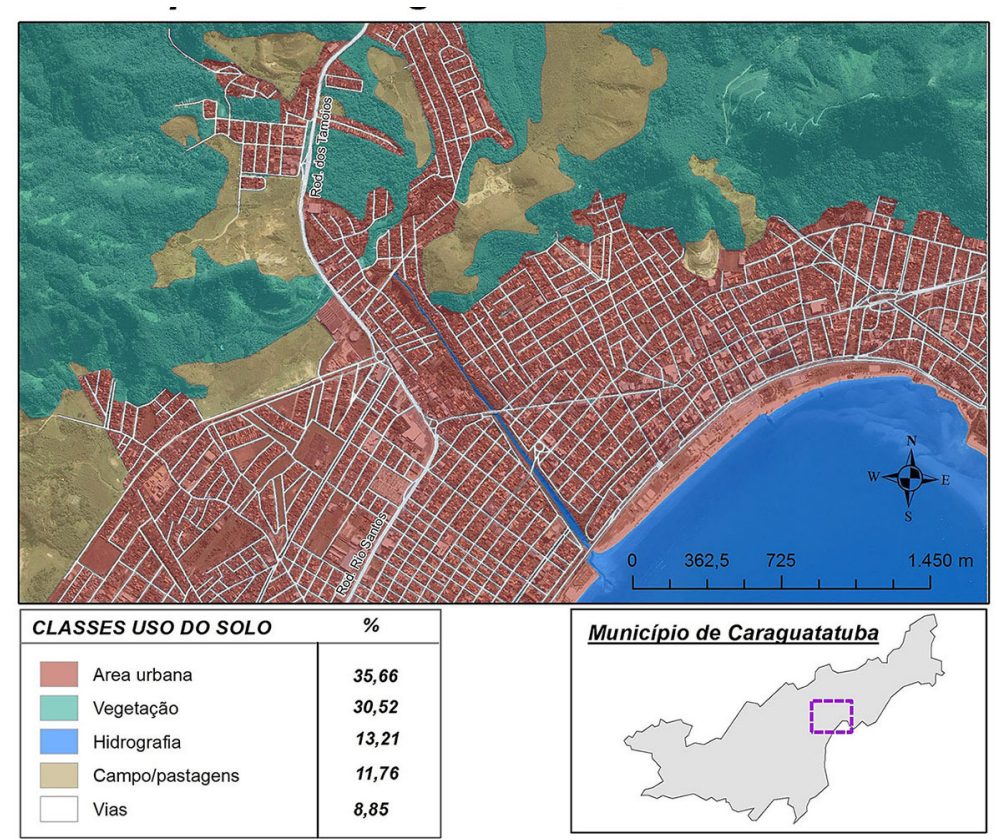

Fonte: Google Earth - maio de 2017. Elaboração: Daniel José de Andrade (PPGPLUR - Univap). 
Figura 6 - Uso do solo na rodovia dos Tamoios - Trecho Serra do Mar, Caraguatatuba-SP (2017)

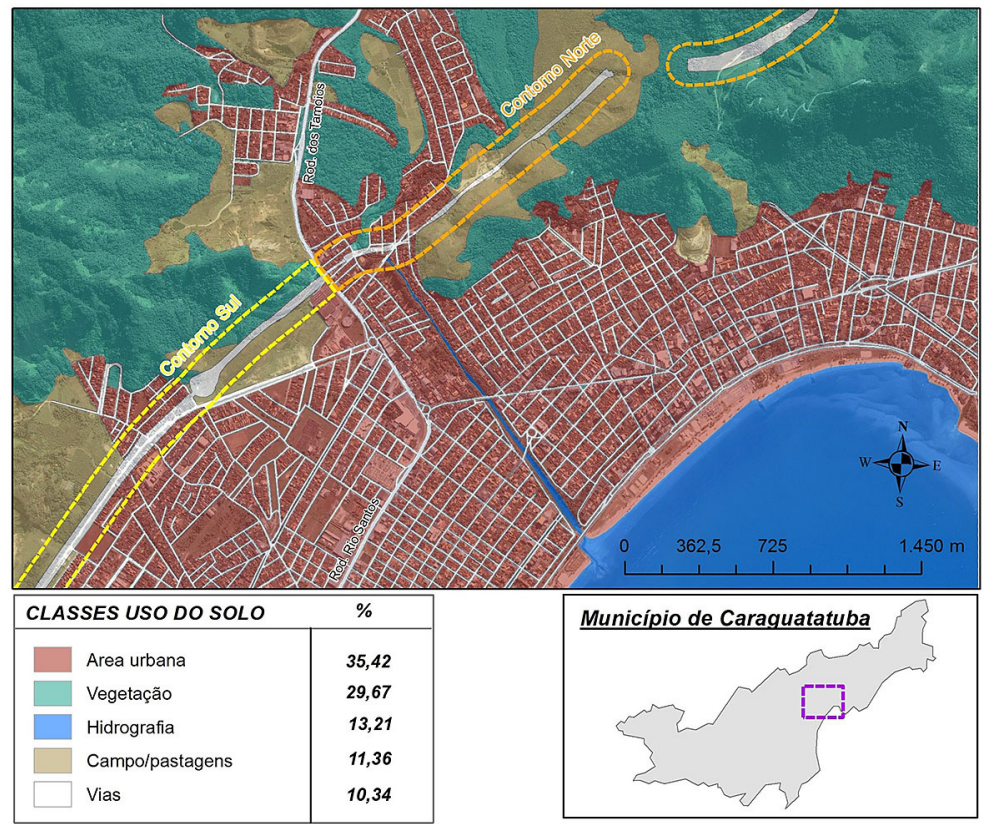

Fonte: Google Earth - maio de 2017. Elaboração: Daniel José de Andrade(PPGPLUR - Univap).

Figura 7 - Uso do solo na rodovia dos Tamoios - Trecho do Contorno Sul, Caraguatatuba-SP (2011)
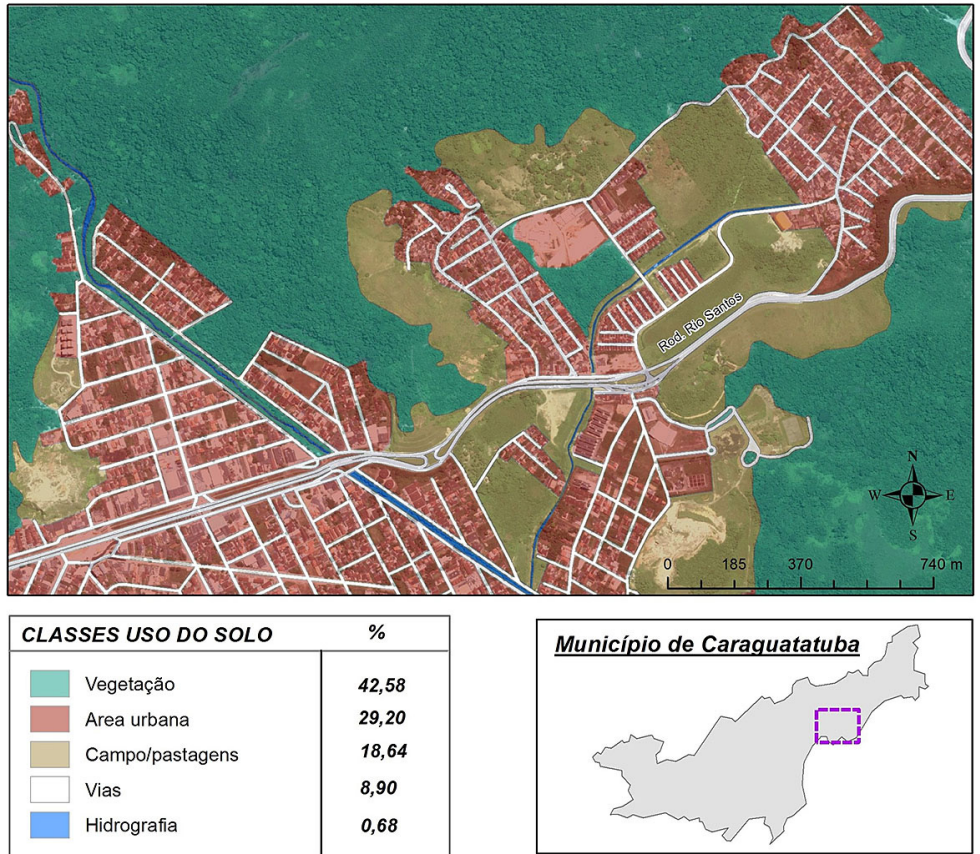

Fonte: Google Earth - maio de 2017. Elaboração: Daniel José de Andrade(PPGPLUR - Univap). 
Figura 8 - Uso do solo na rodovia dos Tamoios - Trecho do Contorno Norte, Caraguatatuba-SP (2017)

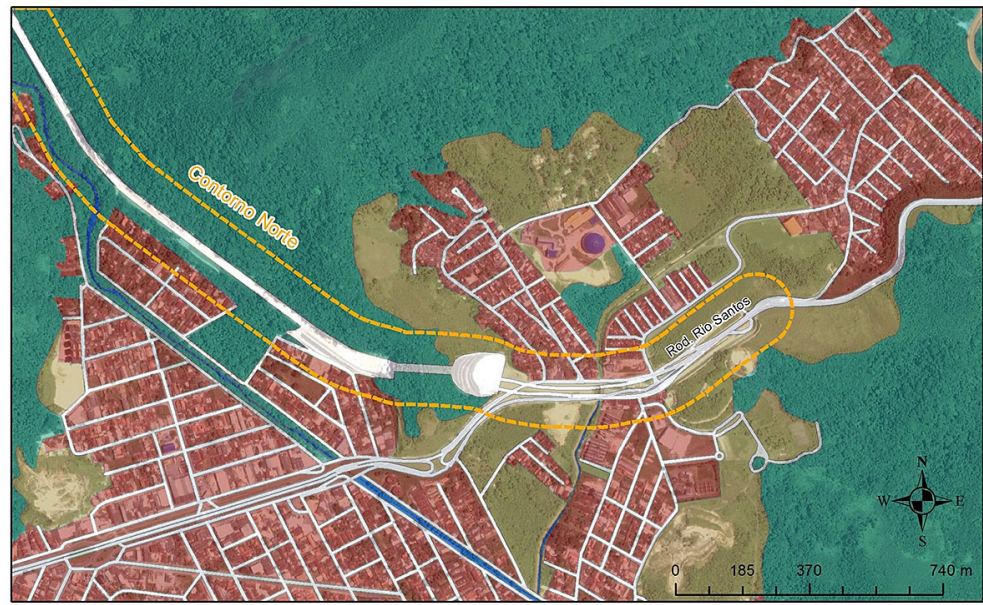

\begin{tabular}{|c|c|}
\hline CLASSES USO DO SOLO & $\%$ \\
\hline Vegetação & 40,99 \\
\hline Area urbana & 29,22 \\
\hline Campo/pastagens & 18,75 \\
\hline Vias & 10,48 \\
\hline Hidrografia & 0,56 \\
\hline
\end{tabular}

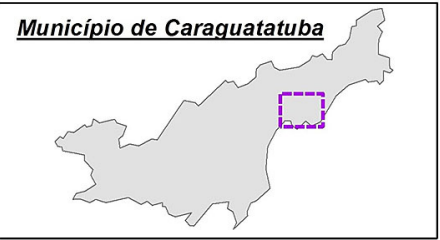

Fonte: Google Earth - maio de 2017. Elaboração: Daniel José de Andrade (PPGPLUR - Univap).

São Sebastião. Juntos, constituem uma área urbana densamente ocupada e predominantemente residencial, localizada entre o PESM e as instalações da Petrobrás, onde, de acordo com o Parecer (Cetesb, 2012a, p. 64), "o impacto de desapropriação e reassentamento será mais crítico". As Figuras 9 e 10 mostram o período anterior e posterior ao início obra de construção do trecho suspenso da rodovia dos Tamoios respectivo ao Contorno Sul, que perpassa a área correspondente ao bairro do Morro do Abrigo.

Desde o início, o projeto de duplicação e ampliação da rodovia dos Tamoios objetivava maior articulação dos municípios litorâneos da RMVPLN com outras localidades da própria região, bem como com outras localidades do País. Referente ao Contorno Sul da Rodovia, pode-se afirmar que foi projetado com vistas a atender aos projetos de ampliação do porto de São Sebastião, considerando principalmente a ampliação do terminal multicargas e do Terminal Marítimo Almirante Barroso (Tebar) da Petrobrás, este último, nas demandas relacionadas ao pré-sal.

Desde a sua criação em 2007, a Companhia Docas de São Sebastião uma sociedade de economia mista e autoridade portuária responsável pela administração e exploração do porto de São Sebastião, disponibiliza relatórios financeiros anuais sobre os fluxos econômicos e de mercadorias, entre outros. 
Figura 9 - Uso do solo na rodovia dos Tamoios - Trecho do Contorno Sul, São Sebastião-SP (2011)

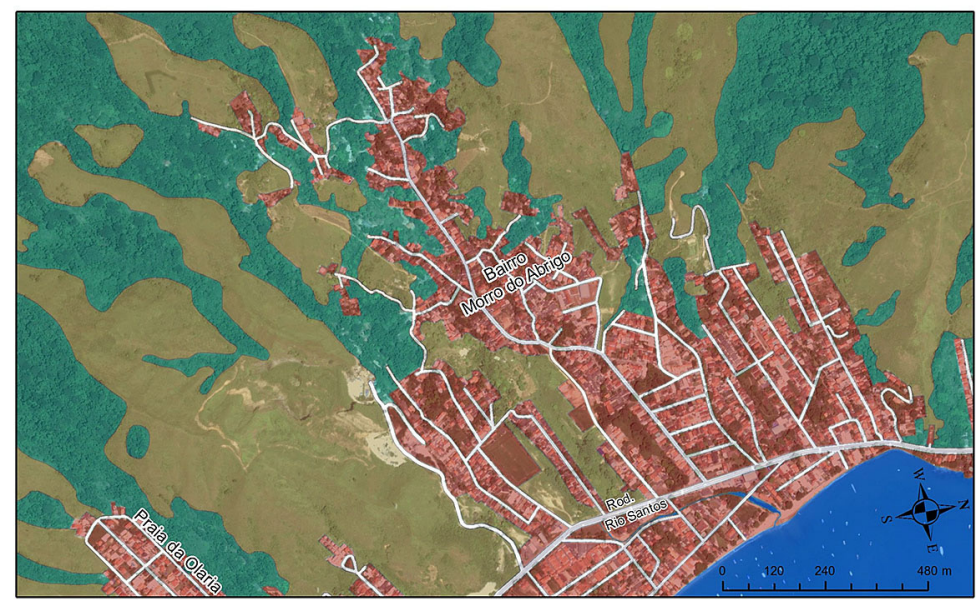

\begin{tabular}{|c|c|}
\hline CLASSES USO DO SOLO & $\%$ \\
\hline Campo/pastagens & 38,33 \\
\hline Vegetação & 29,64 \\
\hline Area urbana & 20,23 \\
\hline Hidrografia & 7,30 \\
\hline Vias & 4,44 \\
\hline
\end{tabular}

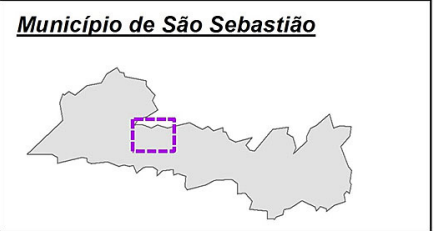

Fonte: Google Earth - maio de 2011. Elaboração: Daniel José de Andrade(PPGPLUR - Univap).

Figura 10 - Uso do solo na rodovia dos Tamoios - Trecho do Contorno Sul, São Sebastião-SP (2017)

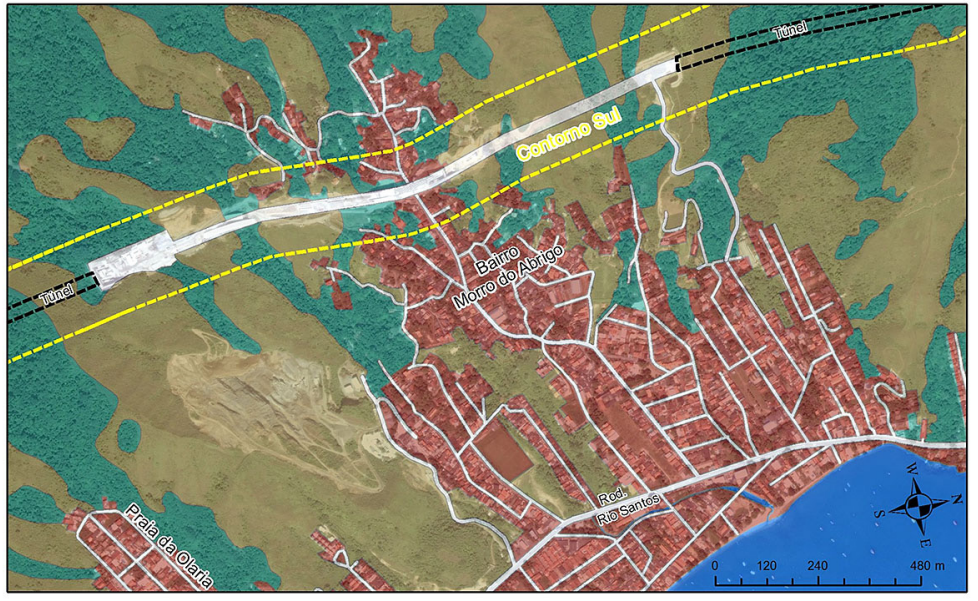

\begin{tabular}{|c|c|}
\hline CLASSES USO DO SOLO & $\%$ \\
\hline Campo/pastagens & 37,36 \\
\hline Vegetação & 28,54 \\
\hline Area urbana & 20,78 \\
\hline Hidrografia & 7,30 \\
\hline Vias & 6,02 \\
\hline
\end{tabular}

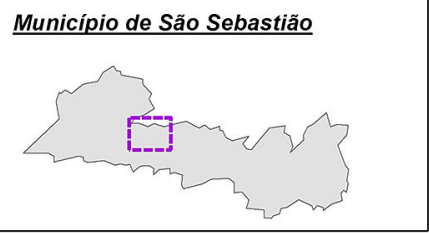

Fonte: Google Earth - maio de 2017. Elaboraçäo: Daniel Josẻ de Andrade(PPGPLUR - Univap). 
Interessa-nos, neste artigo, apresentar a movimentação de cargas, a fim de correlacionar volumes e unidades com a dinâmica produtiva e dos fluxos de mercadorias transitadas na rodovia dos Tamoios.

Dados disponibilizados pelos relatórios de administração da Companhia Docas, autoridade portuária referente aos anos de 2010, 2013 e 2016, mostram que anualmente atracam no porto de São Sebastião navios de diversas localidades do mundo, trazendo toneladas de sais, como a barrilha e o sulfato de sódio, do mineral ulexita e de outros produtos, como o malte e a cevada, utilizados, entre outros tipos, pelas indústrias de fabricação de vidros, celulose, fertilizantes e de bebidas, localizadas na região. Do mesmo modo, tais relatórios revelam que, a partir do porto, são exportados, para diversos países, veículos fabricados por indústrias automobilísticas localizadas na região. 0 volume em unidades de veículos é revelado pelo relatório de 2016, do qual consta que "a movimentação de veículos [...] atingiu 49.167 unidades, sendo 39.208 unidades destinadas à exportação e 9.959 unidades à importação".

Os dados mostram que, no Tebar, operado pela Transpetro, anualmente, uma média de 600 navios que atracam e partem do porto movimentam toneladas de petróleo e derivados. Ainda que grande parte da movimentação para refino e distribuição dos derivados seja realizada via oleoduto, a exemplo do abastecimento de petróleo a partir do porto em direção à Refinaria Henrique Lage, na cidade de São José dos Campos, a distribuição para os municípios da região ocorre via transporte rodoviário. Nesse caso, incluem-se as cidades litorâneas e as atravessadas pela rodovia dos Tamoios, cujos postos distribuidores de combustíveis são abastecidos por caminhões-tanques. Dados da página institucional da Petrobrás revelam que a Refinaria Henrique Lage fornece $80 \%$ do querosene de aviação do mercado nacional, suprindo integralmente o Aeroporto de Internacional de Guarulhos, cujo combustível chega pela rodovia Presidente Dutra.

Ainda no contexto das formas de articulação regional, encontra-se a exploração de gás natural no pré-sal da Bacia de Santos. Ao receber, por meio de gasoduto, a unidade de tratamento de gás instalada no município de Caraguatatuba, processa o gás natural e 0 distribui via gasoduto e, também, por carretas pela rodovia dos Tamoios aos municípios da RMVPLN.

A duplicação da rodovia dos Tamoios e as melhorias e ampliação do porto de São Sebastião constituem um empreendimento vultuoso em infraestrutura de transportes voltado a atender à demanda industrial e às demais capitais existentes na região. É, nesse sentido, que a atual RMVPLN se insere no contexto apresentado por Santos e Silveira (2006, p. 64) que afirmam que "é a circulação em sentido amplo, que viabiliza a criação e a continuidade das áreas de produção".

\section{Considerações finais}

0 estudo do processo de ocupação da região do Vale do Paraíba Paulista mostra que, desde o século XVII, a região caracteriza-se como local de circulação de mercadorias e de pessoas. Tal fato é evidenciado se considerarmos o movimento no século XVIII proveniente das áreas de mineração em direção às cidades litorâneas do estado do Rio de Janeiro e a formação dos 
primeiros núcleos urbanos na região. No final do século XIX, para atender, em especial, à produção cafeeira, foi inaugurada a estrada de ferro Dom Pedro II. Ao atravessar o Vale do Paraíba Paulista, a atual estrada de ferro Central do Brasil conectava os municípios da região as cidades de São Paulo e Rio de Janeiro. Porém, foi no século $X X$, com a inauguração da rodovia Presidente Dutra que, juntamente com a atividade industrial, a região vivencia um intenso processo de urbanização.

Atualmente, além da rodovia Presidente Dutra, a RMVPLN é atravessada por importantes vias, como as rodovias dos Tamoios, Carvalho Pinto e Dom Pedro I, que possibilitam diversos níveis e tipos de articulação entre os seus 39 municípios, ao mesmo tempo que insere a região numa ampla rede de articulação intrarregional e até mesmo internacional, se considerado o porto de São Sebastião e a relativa proximidade com importantes aeroportos do País.

É, neste contexto, que se encontram os projetos de infraestrutura de transportes de ampliação e duplicação da rodovia dos Tamoios e a ampliação do porto de São Sebastião. Constata-se, assim, que, embora tais obras consistam em maior facilidade no escoamento da produção industrial e devam impor maior dinamismo econômico à região, elas podem trazer sérias consequências socioespaciais e ambientais.

Os pareceres técnicos elaborados pela Cetesb nos anos de 2011, 2012 e 2013 e o estudo sobre impactos ambientais desenvolvido em 2015 pelo Instituto de Oceanografia da Universidade de São Paulo referentes às obras da rodovia dos Tamoios e da ampliação do porto de São Sebastião, respectivamente, apontam para os possíveis danos ambientais que tais empreendimentos ocasionarão nos municípios de Caraguatatuba e São Sebastião. A esse respeito, as informações aqui apresentadas mostram que trechos dos Contornos Norte e Sul serão construídos em áreas urbanas densamente ocupadas por bairros dos municípios de Caraguatatuba e São Sebastião. Do mesmo modo, túneis atravessarão trechos da Serra do Mar, e as obras de expansão do porto de São Sebastião se estenderão pela Baía do Araçá, comprometendo o ecossistema local.

Ainda sobre o porto de São Sebastião, vale ressaltar o seu valor estratégico para 0 Brasil, principalmente, após a descoberta do pré-sal. Com base nessa premissa, constata-se que, nas decisões políticas, o interesse econômico prevalece sobre os demais e que, nesse caso, o petróleo foi e é o fator motivador para essas grandes obras de infraestrutura de transportes na região.

Os interesses antagônicos do Estado, dos agentes econômicos e ambientais têm ganhado relevância, na medida em que o primeiro visa ao aumento das arrecadações, o segundo ao aumento das atividades produtivas e o terceiro agente prevê os possíveis danos ambientais a áreas de preservação da Mata Atlântica Paulista.

A obra na rodovia dos Tamoios poderá ter como consequência positiva imediata a facilidade do acesso das demais cidades da RMVPLN às do Litoral Norte, o que certamente incrementará o setor de turismo na região, dinamizando as atividades econômicas e possibilitando novos empreendimentos. A ampliação do porto de São Sebastião aumentará a capacidade de escoamento da produção, intensificando o nível de transações econômicas entre os municípios e destes 
com o mundo, tendo em vista a importância do porto na atual conjuntura do País. No entanto, é necessário afirmar que o rápido aumento nos fluxos de capital nos municípios de Caraguatatuba e São Sebastião, certamente, motivará a migração de pessoas, aumentando a demanda por serviços urbanos básicos e habitação, entre outros. Daí a necessidade da atuação dos poderes públicos locais no efetivo planejamento urbano.

Considerando que as obras iniciadas em 2012 ainda estão em andamento e diante da atual conjuntura política e econômica do País, com forte recessão e queda nos investimentos, muito do que foi planejado precisou e precisará passar por novas releituras e reajustes. Nesse sentido, o que realmente vai acontecer a partir da efetivação dessas obras é incerto.
Como apresentado, neste artigo, são notáveis as transformações ocorridas nos últimos anos em todo o entorno da rodovia dos Tamoios nos trechos de Planalto, Serra, bem como nos trechos referentes aos Contornos Norte e Sul, este último, em direção ao porto de São Sebastião. É, nesse contexto de transformações espaciais, que os interesses do capital se tornam evidentes, conforme as palavras de Harvey (2001, p. 50) "no contexto da acumulação em geral, o aperfeiçoamento do transporte e da comunicação é visto como inevitável e necessário". Desse modo, verifica-se a importância da elaboração de estudos e análises que busquem acompanhar a evolução de tais projetos e que possam, assim, contribuir para a construção de caminhos que conciliem o desenvolvimento econômico e o social na região.

\section{Marco Antonio Henrique}

Universidade do Vale do Paraíba, Programa de Pós-Graduação em Planejamento Urbano e Regional. Instituto de Pesquisa e Desenvolvimento. São José dos Campos, SP/Brasil.

marcoantoniohenriquesjc@gmail.com

\section{Adriane Aparecida Moreira de Souza}

Universidade do Vale do Paraíba, Programa de Pós-Graduação em Planejamento Urbano e Regional. Instituto de Pesquisa e Desenvolvimento. São José dos Campos, SP/Brasil.

adriane@univap.br

\section{Paulo Romano Reschilian}

Universidade do Vale do Paraíba, Programa de Pós-Graduação em Planejamento Urbano e Regional. Instituto de Pesquisa e Desenvolvimento. São José dos Campos, SP/Brasil pauloromano@univap.br 


\section{Notas}

(1) Em 2010, após a descoberta de uma área no litoral brasileiro denominada Bacia de Santos em faixa correspondente às regiões Sul e Sudeste com potencial para a produção de petróleo e gás natural, foi promulgada, pelo governo federal, a lei 12.351, que dispunha, entre outros, sobre o processo de exploração em áreas do pré-sal.

(2) Inaugurado em 1955, o porto de São Sebastião abriga o terminal marítimo Almirante Barroso da Petrobrás Transportes S/A (Transpectro), empresa subsidiária da Petrobrás, para óleo, derivados de petróleo e álcool combustível (Emplasa, 2012).

\section{Referências}

ARTESP - Agência de Transporte do Estado de São Paulo. Disponível em: <http://www.artesp.sp.gov. br/sobre-artesp-historico.html>. Acesso em: 17 maio 2016.

BRASIL (2010). Lei 12.351, de 22 de dezembro de 2010. Exploração e produção de petróleo. Disponível em: <http://www.planalto.gov.br/ccivil_03/_ato2007-2010/2010/lei/L12351.htm>. Acesso em: 20 abr 2017.

CETESB - Companhia Ambiental do Estado de São Paulo (2011). Parecer Técnico 243/2011_IE sobre o EIA_RIMA do Trecho de Planalto da Tamoios. Disponível em: <http://www.cetesb.sp.gov.br/>. Acesso em: 3 maio 2017.

(2012a). Parecer Técnico 352/2012_IE sobre o EIA_RIMA do Trecho de Contorno Sul da Tamoios. Disponível em: < http://www.cetesb.sp.gov.br/>. Acesso em: 3 maio 2017.

(2012b). Parecer Técnico 433/2012_IE sobre o EIA_RIMA do Trecho de Contorno Norte da Tamoios. Disponível em: <http://www.cetesb.sp.gov.br/>. Acesso em: 3 maio 2017.

(2013). Parecer Técnico 221/2013_IE sobre o EIA_RIMA do Trecho de Serra da Tamoios. Disponível em: <http://www.cetesb.sp.gov.br/>. Acesso em: 3 maio 2017.

COMPANHIA DOCAS DE SÃO SEBASTIÃO (2017). [Material Institucional]. Disponível em: <http:// portosaosebastiao.com/>. Acesso em: 15 maio 2017.

CONCESSIONÁRIA TAMOIOS (2017). [Material Institucional]. Disponível em: <http://www. concessionariatamoios.com.br/>. Acesso em: 15 maio 2017.

CONSELHO DE AUTORIDADE PORTUÁRIA (2009). Plano de Desenvolvimento e Zoneamento do Porto de São Sebastião, SP. Disponível em: <www.portodesaosebastiao.com.br/rima/PDZ_Porto_de_ Sao_Sebastiao.pdf>. Acesso em: 16 nov 2016.

COSTA, W. M. (1982). o processo contemporâneo de industrialização: um estudo sobre a expansão da produção industrial em território paulista. Dissertação de Mestrado. São Paulo, Universidade de São Paulo. 
DERSA - Desenvolvimento Rodoviário S/A. (2017). [Material Institucional]. Disponível em: <http:// www.dersa.sp.gov.br/empreendimentos/GrupoEmpreendimento.aspx?idGrupo=1>. Acesso em: 19 abr 2017.

EMPLASA - Empresa Paulista de Planejamento Metropolitano S.A. (2012). Região Metropolitana do Vale do Paraíba e Litoral Norte. Disponível em: <http://www.emplasa.sp.gov.br/emplasa/index. asp>. Acesso em: 4 nov 2014.

HARVEY, D. (2005). A produção capitalista do espaço. São Paulo, Annablume.

IBGE - Instituto Brasileiro de Geografia e Estatística (2010). Disponível em: <http://www.ibge.gov.br>. Acesso em: 22 maio 2017.

INSTITUTO OCEANOGRÁFICO DA UNIVERSIDADE DE SÃO PAULO (2015). Parecer científico sobre a ampliação do Porto de São Sebastião. Disponível em: <http://www.io.usp.br/index.php/ noticias/47-editoria-io/899-parecer-cientifico-sobre-a-ampliacao-do-porto-de-sao-sebastiao>. Acesso em: 3 jan 2017.

MEC - MINISTÉRIO DA EDUCAÇÃO (2015). [Material Institucional]. Disponível em: <http://www.mec. gov.br/.> Acesso em: out 2015.

MÜLLER, N. L. (1969). O Fato Urbano na Bacia do Rio Paraíba - São Paulo. Rio de Janeiro, IBGE.

PESM - Parque Estadual da Serra do Mar. (2017). [Material Institucional]. Disponível em: <http:// www.parqueestadualserradomar.sp.gov.br/pesm/>. Acesso em: 22 maio 2017.

PETROBRÁS - Petróleo Brasileiro S.A. [Material Institucional]. Disponível em: <http://www.petrobras. com.br/pt/>. Acesso em: 22 maio 2017.

PORTO DE SÃO SEBASTIÃO - [Material Institucional]. Disponível em: <http://www.portodesaosebastiao. com.br/pt-br/material-institucional.asp>. Acesso em: 4 maio 2016.

SANTOS, M. e SILVEIRA, M. L. (2006). O Brasil: território e sociedade no início do século XXI. Rio de Janeiro, Record.

SÃO PAULO (2012). Lei Complementar Estadual 1.166, de 9 de janeiro de 2012. Cria a Região Metropolitana do Vale do Paraíba e Litoral Norte. Disponível em: <http://www.al.sp.gov.br/ norma/?id=165017 >. Acesso em: 1o maio 2014.

SEADE - Fundação Sistema Estadual de Análise de Dados (2017). [Material Institucional]. Disponível em: <http://www.seade.gov.br>. Acesso em: 18 set 2017.

SOUZA, A. A. M. (2008). A especialização do lugar: São José dos Campos como centro da tecnologia aeroespacial do Brasil. Tese de Doutorado. São Paulo, Universidade de São Paulo.

TRANSPETRO - Petrobrás Transportes S/A. (2017). [Material Institucional]. Disponível em: <http:// www.transpetro.com.br>. Acesso em: 22 maio 2017.

Texto recebido em 25/maio/2017

Texto aprovado em 8/ago/2017 